ÉGYPTE

monde arabe

\section{Égypte/Monde arabe}

1 | 1999

L'expédition de Bonaparte vue d'Égypte

\title{
L'émir mamelouk et le général français
}

L'histoire de la principauté de Girgâ à travers les correspondances de Murâd bey

\section{Nâsir Sulaymân}

\section{(2) OpenEdition}

\section{Journals}

Édition électronique

URL : https://journals.openedition.org/ema/748

DOI : $10.4000 /$ ema.748

ISSN : 2090-7273

\section{Éditeur}

CEDEJ - Centre d'études et de documentation économiques juridiques et sociales

\section{Édition imprimée}

Date de publication : 30 juin 1999

Pagination : 71-98

ISBN : 2-87027-773-3

ISSN : $1110-5097$

Référence électronique

Nâsir Sulaymân, "L'émir mamelouk et le général français », Égypte/Monde arabe [En ligne], 1 | 1999, mis en ligne le 08 juillet 2008, consulté le 07 juillet 2022. URL : http://journals.openedition.org/ema/ 748 ; DOI : https://doi.org/10.4000/ema.748

Ce document a été généré automatiquement le 7 juillet 2022

Tous droits réservés 


\section{L'émir mamelouk et le général français}

L'histoire de la principauté de Girgâ à travers les correspondances de Murâd bey

\section{Nâsir Sulaymân}

1 Avec la signature, le 5 avril 1800, du traité de paix et d'alliance négocié entre Murâd Bey et le général Kléber, s'ouvre une nouvelle page des relations entre les Mamelouks et les Français. À partir de cette date, de nombreuses lettres seront échangées entre les deux parties et ce sont ces correspondances qui font l'objet de la présente étude. Nous nous proposons d'en montrer l'importance historique, de cerner les aspects par lesquelles elles se distinguent des autres sources contemporaines, et de voir dans quelle mesure elles peuvent éclairer certains aspects de l'histoire de la Haute-Égypte (Sa'îd) restée, faute de documents, largement méconnue. 


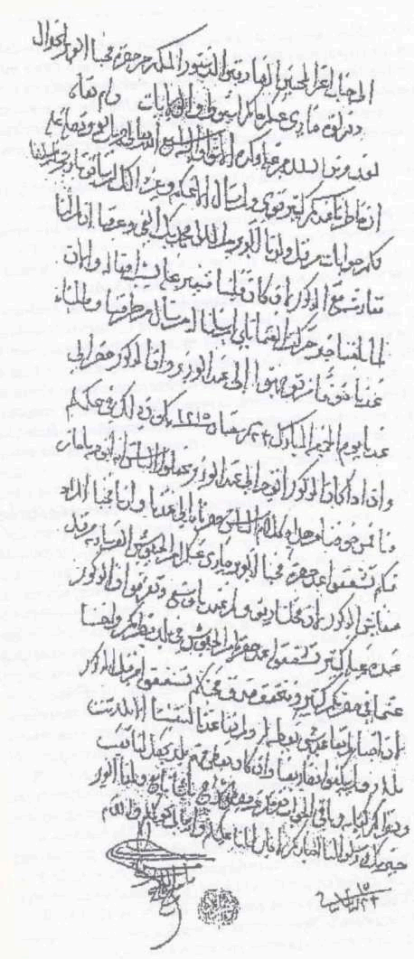

2 Jusqu'ici, les études sur les relations de Murâd bey avec l'expédition d'Égypte ont généralement fait la part belle à la résistance du chef mamelouk durant les deux premières années de l'occupation, et réduit la période qui suit la signature du traité de paix à quelques indications sur la position du général Menou à l'égard des contacts de Murâd bey avec le camp ottoman et l'irritation que lui causa une lettre que la Sublime Porte avait fait parvenir à ce dernier par les soins de 'Uthmân bey al-Bardîsî. L'étude de Nabîl al-Tûkhî ${ }^{1}$ est la première à s'appuyer, entre autres sources, sur les correspondances de Murâd. Elle insiste surtout sur leur aspect politique : l'hostilité de l'émir aux Ottomans et l'activité qu'il déploya pour faire parvenir à la partie française des renseignements militaires relatifs aux forces anglo-ottomanes. Mais ces renseignements, pour importants qu'ils soient, ne sont pas, à notre avis, ce qui en constitue l'intérêt majeur, d'autant que les sources françaises offrent, sur le même sujet, une information abondante ${ }^{2}$. Une relecture de cet ensemble épistolaire et l'examen attentif de ce qui n'est parfois qu'allusif permet, par comparaison, chaque fois que cela est possible, avec les informations fournies par d'autres archives, d'en révéler des aspects inédits, notamment sur l'organisation administrative de la province (wilâya) de Girgâ et les échanges qu'elle entretenait avec les régions (iqlîm) placées sous autorité française.

Le fonds d'archives

3 Les correspondances de Murâd bey font partie d'un ensemble de documents relatifs à l'expédition française appartenant à la Bibliothèque centrale de l'université du Caire. La date de leur achat et de leur entrée dans les fonds de la bibliothèque est inconnue. Il en existe un index, dont l'original est conservé en France, et qui fut publié sous le titre de Napoléon Ier et son temps. Outre la présentation descriptive des documents, cet index en donne le classement archivistique précis. Il est organisé selon un plan 
thématique : toutes les lettres de Murâd bey au général Donzelot ${ }^{3}$, par exemple, se trouvent avec les documents relatifs à la Haute-Égypte, sur toute la durée de l'expédition ${ }^{4}$.

4 L'auteur de cette compilation indique que les lettres sont au nombre de 69, tenant en 135 feuilles 5 . Mais un certain nombre d'entre elles ont été perdues, puisque le carton qui les rassemble n'en contient plus que 43 , tenant en 73 feuilles, à quoi il convient d'ajouter un autre ensemble, copié de l'original perdu, contenant 9 lettres et tenant en 12 feuilles $^{6}$. Au total, ce sont 52 lettres tenant en 85 feuilles qui font l'objet de la présente étude, 17 lettres tenant en 50 feuilles ayant été perdues. L'étude des fonds relatifs à l'expédition conservés aux Archives nationales (Dâr al-wathâ'iq al-qawmiyya) pourrait permettre de retrouver la trace de certaines de ces correspondances disparues. Il était en effet d'un usage habituel, au moment de l'expédition, de traduire en français les correspondances reçues, tout comme l'ensemble des pétitions arabes. On a pu ainsi retrouver deux lettres envoyées par Murâd bey à la partie française. La première est adressée au général Damas, chef d'état-major de l'armée française ${ }^{7}$. Et si la date de sa rédaction nous est inconnue, il ressort de son contenu qu'elle a été écrite à la suite de la mort de Kléber, et qu'elle a dû être envoyée, en conséquence, durant la dernière semaine du mois de juin $1800^{8}$. La seconde lettre, quant à elle, est adressée à Donzelot $^{9}$, en date du 3 août 1800 . Le nombre des lettres soumises à cette étude s'élève donc à 54, et le nombre des lettres perdues, par comparaison avec l'index français, est de 15.

5 On ne peut évidemment rien savoir du contenu des documents perdus. Dans ce qui subsiste, toutes les correspondances ne concernent pas le seul Murâd. On trouve aussi de nombreuses lettres envoyées par d'autres émirs mamelouks au général Donzelot ${ }^{10}$. Le fonds, en revanche, ne contient aucune des lettres adressées par Donzelot aux émirs. Elles étaient pourtant rédigées en arabe et l'index français ${ }^{11}$ stipule qu'elles faisaient partie du même ensemble : un grand nombre d'entre elles figure sans doute parmi les documents disparus. Les numéros portés sur les documents ne fournissent aucun indice sur leur nombre total: ils correspondent simplement à la pagination des feuilles contenues dans le carton. Ils ne suivent pas, du reste, l'ordre chronologique de la rédaction. Ainsi, par exemple, le numéro 113 correspond à la lettre la plus ancienne (21 dhû al-hijja 1214/15 mai 1800) et le numéro 112 à la plus récente (23 dhû al-qa'da $1215 / 7$ avril 1801$)^{12}$, tandis que deux lettres que Murâd bey envoya en juin 1800 portent les numéros 49 et 128.

6 L'existence de ces lacunes explique les difficultés que l'on a parfois à trouver un lien entre les correspondances ou à couvrir certaines périodes. La disparition des lettres envoyées par le général Donzelot durant la période de paix avec les Mamelouks ${ }^{13}$ est particulièrement gênante. Trois documents seulement ont pu être retrouvés dans les fonds de l'université du Caire ${ }^{14}$. Postérieurs au débarquement anglo-ottoman, ils sont de peu de profit puisque les lettres de Murâd bey, que la mort enlève au même moment, manquent aussi pour cette période de la guerre qui voit s'amorcer le repli des Français de la Haute-Égypte vers Le Caire. Il reste donc indispensable de recourir à d'autres sources pour comprendre de façon précise certains détails restés obscurs dans les correspondances.

La forme des correspondances

7 Les lettres se présentent sous la forme de "pétitions ", puisqu'elles consistent en réclamations, tant du côté français que du côté mamelouk. Leur dimension est le plus 
souvent de 21/22 centimètres. Les marges varient d'une lettre à l'autre, en fonction du sujet traité. Généralement, elles laissent de grands blancs sur tous les côtés, que le drogman particulier de Donzelot utilisa pour la traduction du texte. On notera que le texte, dans la plupart des cas, se présente en colonnes, qui peuvent compter jusqu'à 18 lignes. Il arrive aussi qu'une page comporte deux colonnes semblables, séparées par un espacement régulier, d'équilibre formel si net qu'il saute aux yeux, comme si, d'une colonne à l'autre, une règle imaginaire avait réglé la succession des lignes. Dans ce cas, les blancs laissés aux marges des feuilles sont plus étroits. Lorsque les lettres concernent des informations relevées par les espions de Murâd bey et relatives au camp de l'armée anglo-ottomane ou aux mouvements de la flotte anglaise en mer Rouge, elles comportent généralement deux feuilles distinctes ${ }^{15}$. Il était habituel, en effet, de n'écrire que sur une seule face. Et il est évident qu'il en a été de même pour toutes les lettres. Il faut sans doute voir là une des causes de leur désorganisation et de leur dispersion hors du carton principal numéro 119 ; on a retrouvé cinq lettres ${ }^{16}$ à l'intérieur du carton numéro 256.

Le papier est celui utilisé alors en Égypte : un papier lisse ${ }^{17}$, remarquablement souple, tirant sur le jaune foncé et faisant ressortir le noir de l'encre avec laquelle toutes les lettres ont été écrites. On retrouve cette sorte de papier pour un nombre non négligeable de documents relatifs à l'expédition dans les fonds de la Bibliothèque centrale, signe que l'administration française en Haute-Égypte (et peut-être dans d'autres régions) utilisait ce papier de fabrication égyptienne, très différent des papiers filigranés qu'utilisait l'administration française pour la publication de ses ordres du jour ${ }^{18}$.

Toutes les lettres sont écrites en arabe dialectal et il faut souligner ici l'intérêt de ces documents pour l'étude de la langue et de l'usage épistolaire des personnels de l'administration à la fin $d u x^{x} I_{I I}{ }^{e}$ et au début $d u$ xIX ${ }^{e}$ siècle. Lorsque les lettres arrivaient, elles étaient immédiatement apportées au drogman personnel du général Donzelot qui, ne connaissant pas le français, les traduisait en italien ${ }^{19}$. Il semble qu'on ait utilisé pour les travaux de traduction, tant du côté français que du côté mamelouk, les services de Grecs sachant les deux langues, arabe et italienne. Dans les deux cas, ces fonctions leur valaient d'obtenir d'importantes positions ${ }^{20}$. Alors que les traductions italiennes, qu'elles soient portées sur les lettres elles-mêmes, comme c'est le cas généralement, ou qu'elles soient transcrites sur des feuilles séparées, existent pour presque toutes les correspondances, les traductions françaises sont, elles, perdues pour la plupart des originaux. Certaines figurent peut-être dans les fonds des Archives nationales. Nous y avons trouvé, par exemple, une lettre de Murâd bey au général Donzelot écrite en français qui ne peut être, par le contenu comme la date de rédaction, que la traduction de l'original arabe numéro $109^{21}$. Il semble que l'utilisation de la langue arabe n'était pas le privilège des seuls Mamelouks, mais que du côté français aussi on l'utilisait dans les correspondances adressées aux émirs mamelouks. Parmi les documents de l'université du Caire, trois lettres adressées à Murâd bey sont écrites en arabe : ce sont des brouillons surchargés de ratures et de corrections. On remarquera à leur sujet que le drogman n'a pas seulement conservé le sens de la lettre mamelouke, mais qu'il en a aussi repris le style épistolaire ${ }^{22}$. 


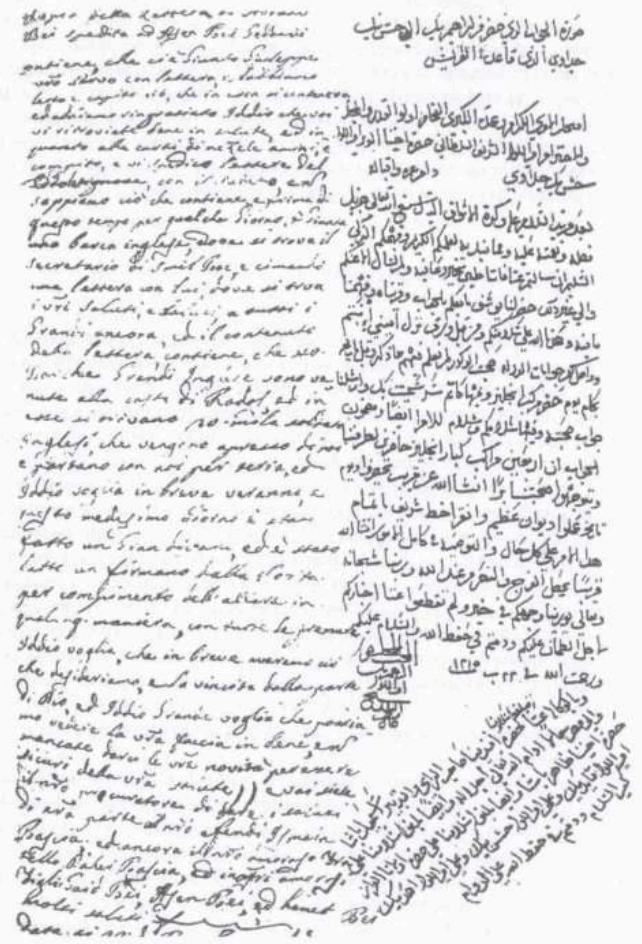

L'acheminement du courrier

L'échange régulier de correspondances constituait un moyen de communication privilégié pour le rapprochement des deux alliés et le traitement en commun des problèmes qui ne manqueraient pas de se poser à l'avenir. Il était donc indispensable que les deux parties se missent d'accord sur la façon dont elles se feraient parvenir toute nouvelle information obtenue. Les Français, d'autre part, savaient que Murâd bey gardait des contacts avec les Mamelouks du camp ottoman et qu'ils pouvaient en tirer parti pour connaître avec précision les intentions et les plans de leur ennemi. Aussi Kléber permit-il à Murâd bey de poursuivre son travail de renseignement après la signature du traité de paix ${ }^{23}$. Tout cela, assurément, encouragea les échanges épistolaires. On s'écrivait de tous côtés. De Syrie, Hasan bey al-Jiddâwî et Ibrâhîm bey envoyaient à Girgâ des lettres que Murâd bey devait transmettre à Donzelot ${ }^{24}$, nommé par Kléber au gouvernement de la province d'Asyût et de Minyâ, contiguë à celle de Girgâ, et qui avait mission de le représenter dans les relations avec les émirs de HauteÉgypte $^{25}$. Pour mener à bien cette mission, Donzelot devait s'informer de près de toutes les demandes que pourrait faire cet émir au général en chef. Ce dont Kléber avait bien perçu l'importance, puisqu'il écrivit à Donzelot: "Je vous ai envoyé une copie de la lettre que j'ai reçue de Murâd bey, et une copie de la réponse que je lui ai faite. J'agirai en cela toujours de la même façon, de sorte que vous soyez parfaitement informé. $»^{26}$

11 Cette décision était d'importance. Donzelot se sentit autorisé à prendre connnaissance du contenu des lettres de Murâd bey à l'état-major avant qu'elles ne parviennent au Caire. Il pouvait ainsi mieux informer ses supérieurs en leur faisant part de ses impressions et de ses commentaires sur tout ce que Murâd bey leur demandait. Il en informa Murâd et lui expliqua que son intervention visait à lui offrir ses conseils et sa médiation dans ses relations avec l'état-major. Il le pressa aussi d'intensifier 
l'acheminement du courrier entre eux, de façon à échanger des nouvelles presque quotidiennement ${ }^{27}$. L'émir de Girgâ salua cette initiative, l'assurant qu'il avait eu la même idée et qu'il se proposait de la lui exposer, convaincu qu'il était de l'importance qu'il y avait à consolider leur coopération. «Et si Dieu veut, - qu'Il soit exalté ! -, tout ce que nous demanderons sera entre vos mains et ce que vous voudrez, qu'il s'agisse d'un service ou d'autre chose, faites-le nous savoir, nous l'exécuterons sans retard. $»^{28}$ Les nombreuses lettres qui suivent viennent confirmer le respect de l'engagement ainsi pris $^{29}$. De fait, Murâd bey ne tarissait pas d'éloge sur Donzelot chaque fois que les lettres que le général français adressait au Caire étaient accompagnées d'une lettre de lui ${ }^{30}$. Donzelot, de son côté, faisait de même quand il accompagnait une lettre de l'état-major du Caire à Murâd bey d'un commentaire expliquant ce que désirait le commandement français ${ }^{31}$. C'est sur ce mode que s'organisa le cadre général de la poste entre le gouvernement de Girgâ et les provinces placées sous autorité française.
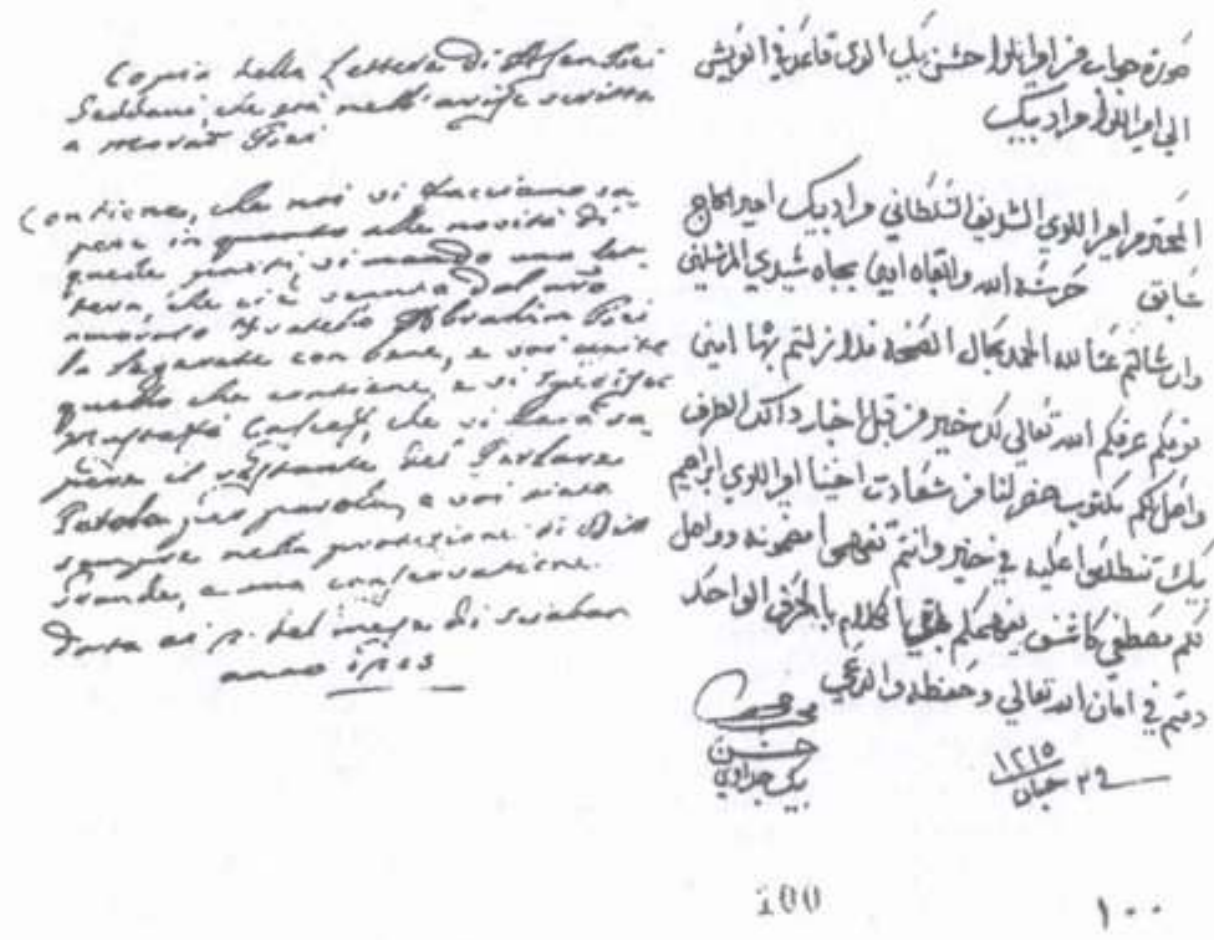

La disparition de certaines lettres de Murâd bey à Donzelot souleva le problème des messagers. Et si Murâd bey refusait de blâmer Donzelot, disant que la faute lui en revenait à lui et aux gens qu'il utilisait ${ }^{32}$, il était d'avis de charger de la responsabilité du transport du courrier des personnes précises, dignes de confiance et susceptibles de garder le secret. Les deux parties se mirent d'accord sur la règle selon laquelle serait mentionné le nom du porteur. Les lettres nous font ainsi découvrir les noms des plus hauts personnages mamelouks, comme 'Uthmân bey al-Bardîsî, Ibrâhîm agha katkhuda (lieutenant de Murâd bey), Mustafâ Sirâj pacha, Sâlim al-Tawâshî, Hasan agha, etc. Il y avait probablement autant de messagers en face, auprès de Donzelot. Il est assuré que Murâd n'hésitait pas à envoyer des personnes de son entourage direct dans des régions sous commandement français. Elles étaient chargées d'acheminer certaines lettres ${ }^{33}$. 
Les porteurs des lettres de Donzelot ou de l'état-major, en revanche, n'étaient pas nécessairement des hommes de Murâd bey : il y avait aussi des officiers français ${ }^{34}$.

Que Murâd bey ait chargé certains émirs de sa garde particulière de l'acheminement de ses messages n'est, bien sûr, pas dépourvu de signification. C'était non seulement une garantie que les lettres arriveraient bien à destination, mais aussi un moyen de ne pas mettre dans ses lettres tout ce qu'il voulait faire savoir. Murâd avait l'habitude de confier les détails - et peut-être les plus importants - au porteur de la lettre ou, selon sa propre expression, "à la lettre qui a une langue $»^{35}$. Il faut dire que les espions de tous bords, organisés en un vaste réseau, se livraient une lutte acharnée et qu'il fallait, pour empêcher toute infiltration, que les messagers soient craints et connaissent les routes les plus sûres. La vitesse d'exécution du transport commandait la multiplication des personnes chargées de ces missions. Il était rare que l'une des parties tardât à répondre à l'autre ${ }^{36}$, parce que qu'il ne s'agissait pas d'une poste ordinaire : les lettres répondaient d'abord à une exigence politique et sécuritaire. L'arrivée d'une lettre importante, à temps ou en retard, avait nécessairement des effets sur l'orientation des décisions prises par chacune des deux parties, liées par les mêmes intérêts et qui devaient faire face aux mêmes menaces.

Pour autant, toutes les lettres n'étaient pas de nature politique; elles se caractérisent au contraire par la variété des sujets traités, notamment en matière administrative et financière. Deux thèmes majeurs s'en dégagent: l'administration mamelouke du gouvernement de Girgâ d'une part ; le contrôle de l'économie de Girgâ et ses relations avec la province d'Asyût et de Minyâ placée sous autorité française, d'autre part.

L'administration de la province de Girgâ par les Mamelouks

Les correspondances nous permettent de suivre deux aspects importants de l'organisation administrative de la principauté mamelouke de Girgâ. Le premier concerne l'attribution de concessions foncières et fiscales (kushûfiyyât et muqâta'ât) aux émirs et gouverneurs de district (kâshif, pl. kushshâf) et la crise qu'elle provoqua, le nombre des dévolutaires dépassant celui des circonscriptions que comptait la principauté (wilâya). Le second concerne les mesures qui furent prises pour contrôler et organiser les mouvements des Mamelouks entre la principauté de Girgâ et les provinces voisines.

Murâd Bey et la distribution des concessions

On sait qu'administrativement l'Égypte, avant le traité Murâd bey-Kléber, se trouvait divisée en huit arrondissements (mudîriyya) et que Qinâ, Girgâ et Asyût formaient la première de ces unités ${ }^{37}$. L'octroi à Murâd bey du gouvernement de Girgâ ne pouvait que modifier le découpage du territoire; un ordre du jour promulgué par Kléber entérine, de fait, cette situation nouvelle, en faisant d'Asyût et de Minyâ la première des provinces relevant de l'autorité française ${ }^{38}$. L'article premier du traité de paix, relatif à l'étendue géographique de la principauté concédée aux Mamelouks, la définissait comme allant du village (nâhya) de Balsafûra ${ }^{39}$ au nord, à Assouan au sud. Mais si le traité accordait à Murâd toute liberté de gouverner sa principauté à sa guise, il comportait cependant une clause qui lui faisait obligation de payer l'impôt foncier (kharâg) selon un montant déterminé, dont il devait s'acquitter auprès du Trésor français, et qui lui interdisait, en outre, d'apporter la moindre modification au régime des terres ou de procéder à leur redistribution. Cette clause confirme que Murâd ne jouissait pas d'une indépendance complète et que sa principauté ne formait pas une entité distincte. Le traité, en un mot, ne lui reconnaissait que "l'autorité politique 
(sultat al-hukm) et la jouissance du revenu fiscal $»^{40}$. Du reste, cette idée de concentrer le pouvoir des Mamelouks dans la moitié sud de la Haute-Égypte (al-Sa'îd al-aqsâ), à l'exclusion de toute autre province, n'était pas seulement le résultat des négociations de paix menées entre les deux parties : elle avait ses racines dans les plans préparés par Bonaparte, en vue de la signature d'un accord de paix avec Murâd bey, dès les lendemains de la conquête, et qui prévoyaient, déjà, de lui octroyer le gouvernement de Girgâa ${ }^{41}$.

17 Murâd bey prend en main l'administration de la nouvelle principauté au début du mois de mai $1800^{42}$. Avant la fin du mois de juin, il a pratiquement achevé l'attribution à ses émirs (sandjak-beys et kushshâf) des circonscriptions administratives et fiscales, comprises dans les limites de sa province. On sait que Girgâ comptait, avant l'expédition, quatorze circonscriptions ${ }^{43}$ et que ce nombre descendit au-dessous de dix lorsqu'on en détacha le district d'Asyût. Le grand nombre de sandjak-beys et de kushshâf accompagnés de leurs maisons conduisit Murâd bey à émietter les anciennes circonscriptions, de façon à s'attacher tous les émirs et à maintenir entre eux une forme d'équilibre, le niveau de leurs revenus, provenant de taxes diverses, étant fonction des unités administratives et financières qui leur étaient attribuées. Les efforts qu'il faisait par ailleurs pour se rallier les émirs mamelouks de Syrie ne pouvaient qu'aggraver le problème et l'amplifier. À la fin de juin 1800, il était clair que tous les villages (nâhya) et les hameaux de sa province n'y suffiraient pas et il dut en référer à la partie française : ses correspondances sont particulièrement éclairantes sur ce point et montrent l'urgence des mesures à prendre.

On connaît par ces dernières les propositions qu'il fit à Donzelot. Elles consistaient, pour l'essentiel, à demander l'ajournement de l'impôt (mîrî) pour l'année 1215: "Acceptez nos excuses pour l'année en question, car les temps sont difficiles. Nous nous en remettons à Dieu - qu'Il soit exalté ! -, et à votre bienheureuse Seigneurie. $»^{44}$ Pour appuyer sa demande, Murâd envoya de nombreuses copies conformes de sa lettre à des généraux de l'expédition ${ }^{45}$. Il avait l'habitude, comme nous l'avons vu plus haut, de ne pas mettre dans ses lettres tout ce qu'il désirait faire savoir, et de taire, en particulier, les informations les plus importantes. Il se contentait, alors, d'indiquer dans sa lettre que le porteur avait un message oral : «Et nous ne saurions trouver de repos pour nos moyens d'existence, si ce n'est de votre Seigneurie (...) l'émir Ibrâhîm, notre katkhuda, vous fera savoir le reste du message $»^{46}$. Le reste du message portait sur des villages dont il demandait le rattachement à la principauté de Girgâa ${ }^{47}$.

19 La disparition des lettres comprises entre les numéros 68 et 72 ne nous permet pas de connaître la suite qui fut donnée à cette demande par l'état-major français. Les négociations conduites durant quatre jours amenèrent, en tout cas, une modification des conditions financières faites au chef mamelouk. On lui accorda quelques villages de Sûhâg qui se situaient en dehors des limites de son gouvernement contre une augmentation de $60 \%$ du montant de l'impôt payé en espèces (kharâg) ${ }^{48}$ ! Menou profitait ainsi du besoin pressant que Murâd bey avait de ces villages pour restituer au Trésor français une partie de ce qu'il avait perdu en cédant son monopole sur les revenus fiscaux de la fertile province de Girgâ ${ }^{49}$. Mais ni l'ajournement de l'impôt pour l'année 1215/1800 ni l'adjonction de quelques villages de Sûhag - grevés en outre d'une surimposition -, ne pouvaient conduire au règlement du problème. Ne serait-ce que parce que le nombre des émirs augmentait à mesure que le temps passait, Murâd bey n'ayant de cesse de susciter dans le camp des forces anglo-ottomanes de nouvelles 
défections. Et puis, il ne s'agissait pas seulement de trouver un nombre suffisant de villages à distribuer, il fallait aussi apaiser la rivalité des émirs sur leur qualité, leur localisation et les revenus qu'ils en escomptaient. Une des lettres fait ainsi état d'une plainte du « général » (amîr liwâ) Sulaymân bey, un des plus grands émirs mamelouks attachés à Murâd, qui, mécontent du village qui lui avait été attribué par l'administration mamelouke, en référa directement à Donzelot et lui demanda de faire pression sur son maître pour qu'il corrige la distribution des concessions. Le général Donzelot intervint, en effet, auprès de Murâd bey pour qu'il accorde à Sulaymân bey soit la ville d'Isnâ, soit celle de Qinâ, soit encore celle d'Akhmîm, l'une ou l'autre, en somme, des plus grandes villes de la province. Mais Murâd bey avait déjà procédé à leur distribution. Il les avait même partagées entre plusieurs émirs, en sorte que la moindre modification soulevait les pires difficultés. Aussi écrivit-il à Donzelot : "Ces localités, mon cher, sont toutes occupées par des Mamelouks (ghuzz); il y a des Mamelouks dans chacune d'entre elles, et il ne convient pas que nous les prenions des mains de ceux qui s'y trouvent, car si nous les leur retirions, ils en feraient toute une histoire et tout un problème; sans cela, nous l'aurions fait pour vous satisfaire et plus encore parce que nous en avons le plus grand besoin $\aleph^{50}$. Il précisa, en outre, qu'il avait pris en considération la plainte de Sulaymân bey et lui avait offert une autre commune, qu'il avait encore refusée. Pour mieux convaincre Donzelot, Murâd bey lui donne des éclaircissements sur le problème dans son ensemble et lui avoue être dans l'incapacité absolue d'entretenir les maisons de vingt à trente émirs « qui sont là, sans le moindre village $»^{51}$.

Murâd bey ne pouvait se permettre un affrontement ni avec le côté français, ni avec les émirs mamelouks qui s'étaient ralliés à lui. Son désir de maintenir l'équilibre d'un côté comme de l'autre le conduisit à se justifier auprès de Donzelot, pour qu'il lui accorde son soutien dans son refus de modifier en quoi que ce soit la distribution des concessions fiscales. C'était une affaire qui pouvait avoir des conséquences dépassant les simples querelles de personnes. Il fallait absolument maintenir la situation en l'état et ne pas risquer un précédent dont les autres émirs eussent pu tirer parti. Par la suite, il fit tout pour empêcher les Mamelouks de se tourner du côté français chaque fois que se produisait, sur un sujet ou un autre, une difficulté. Aussi, lorsque Muhammad bey alAlfî le rejoint, en janvier 1801, en compagnie de douze émirs et de leur suite (soit 25 Mamelouks), Murâd n'hésita pas à reposer la question de l'administration financière. À l'attention des responsables français, il fit valoir qu'il s'était chargé tout seul de rallier à lui les Mamelouks fidèles à la Sublime Porte, qu'il en avait seul supporté les fatigues, alors que c'était pourtant leur but commun; qu'il était de la plus haute importance qu'il ait réussi à rallier les Alfites, qui étaient jusque-là leurs plus farouches ennemis ; et qu'en conséquence, il se permettait de revenir, auprès de Donzelot, sur cette question qu'il avait déjà soulevée quatre mois auparavant. "Vous savez que nousmêmes ne possédons que trois villages et qu'en dehors de cela nous n'avons pas le moindre arpent (qirât), comme vous savez que nos dépenses sont nombreuses et que nous ne pouvons y suffire. Grâce à Dieu nos couleurs sont les vôtres et notre repos est entre les mains de Dieu et les vôtres, et ce que vous exigerez, nous le ferons. " Il finissait sa lettre (voir fac-similé p. 70) en affirmant que si la crise se poursuivait, elle pourrait bien intéresser l'ennemi, qui chercherait à utiliser la situation pour mieux leur nuire; et qu'il craignait que le peu d'empressement que les Français mettaient à accorder le moindre village à l'Alfî ne finisse par le faire repartir là d'où il était venu ${ }^{52}$. 
21 Là encore, la perte d'un certain nombre de lettres entraîne des lacunes qu'il n'est possible de combler que par le recours à d'autres documents. Les Mémoires du Général Reynier - un des grands généraux de l'expédition -, rapportent la conversation qui eut lieu entre le général en chef Menou et 'Uthmân bey al-Bardîsî, l'émissaire que Murâd avait chargé de porter la lettre mentionnée ci-dessus. Cette conversation montre clairement à quel point les informations apportées par Bardîsî provoquent l'irritation de Menou, qui reproche à Murâd de ne pas lui avoir livré l'Alfî, pieds et poings liés, et avec lui ses hommes qu'au contraire il avait armés à leur arrivée à Girgâ ${ }^{53}$. Menou feint délibérément d'ignorer les problèmes de Murâd et lui en impute la responsabilité, dans l'espoir d'entraver sa politique de regroupement et de concentration de toutes forces mameloukes dans sa principauté du Haut-Sa'îd (al-Sa'îd al-aqsâ). On fit savoir à l'émir que sa demande était refusée. Elle ne constituait pourtant pas un précédent, puisque Kléber, déjà, avait attribué à certains de ses lieutenants, comme 'Uthmân bey al-Bardîsî, 'Uthmân cAskar et Husayn Kâshif, des villages de Haute ou de Basse-Égypte, dans des conditions analogues à celles prévues par le traité ${ }^{54}$.

Si le chef mamelouk ne pouvait accomplir de pas décisif dans ses négociations avec les Français, dans le même temps, le besoin pressant où l'administration française se trouvait devait nécessairement la conduire à recourir à leurs services, en tirant profit $\mathrm{du}$ prestige dont ils jouissaient auprès des populations, pour faciliter la mise en recouvrement de l'impôt ou assurer la sécurité et la stabilité dans les campagnes. Cette contrainte établissait entre les deux parties une détente relative, dont les correspondances font état. Le général Donzelot fit ainsi nommer l'émir Salîm, un des proches de Murâd bey, kâshif d'Asyût ${ }^{55}$; il demanda, début avril 1801, qu'on envoie un Mamelouk comme sandjak de Minyâ ${ }^{56}$; permit à certaines familles mameloukes de s'installer à Asyût ou Manfalût ${ }^{57}$; comme il accueillit tous les Mamelouks qui, contraints par la crise, se réfugiaient auprès de lui. Notons que le ralliement aux Français de certains émirs, comme de segments des milices (odjaq) éparpillées dans les campagnes, n'était pas tant le résultat du traité de paix que la conséquence de la politique menée continûment, et depuis le début de l'occupation, par les généraux de l'expédition. Un mois et demi après l'occupation du Caire, un ordre du jour, repris dans les correspondances de Bonaparte, autorisait déjà le général Dizier, qui poursuivait les Mamelouks en Haute-Égypte, à proposer la paix aux beys, en échange de l'obligation qu'il leur serait faite de demeurer sur leurs terres, de s'acquitter de l'impôt et de fournir les Français en chevaux ${ }^{58}$. Et dans le « Mémoire sur le système d'imposition de la Haute-Égypte » rédigé en 1798, nous voyons l'administration française s'appuyer sur les forces locales mameloukes et ottomanes présentes à Isnâ, Girgâ et Asyût, pour les mêmes missions d'administration ou de sécurité59. Même chose dans les premiers décrets pris par Kléber au sujet de l'organisation administrative des provinces, qu'il soutient et étaye en partant du principe que ces soldats sont ceux qui connaissent le mieux le pays et les populations, ceux qui en connaissent le mieux les routes, et que ce sont là des données qui pourraient bien aider au recouvrement de l'impôt ${ }^{60}$; ce que confirmeront, par la suite, les registres de l'impôt, où seront consignées les sommes recouvrées par les kushshâf, les sandjak-beys et les généraux (sirdâr) mamelouks ${ }^{61}$.

Le désir que Murâd avait de placer les meilleurs et les plus fidèles de ses hommes dans des régions placées sous autorité française dit bien son adhésion à la politique menée par l'administration de l'expédition, favorable à l'intégration, sans égard au nombre, des Mamelouks ou des officiers des milices dans son système administratif et financier. 
Au moment même où les Français refusaient de voir dans l'extension territoriale de la principauté de Girgâ la solution au problème administratif et financier dont souffrait l'émir du Sa'îd, celui-ci pouvait escompter tirer doublement parti de la nomination de certains des siens dans les régions proches de Haute-Égypte: tout en donnant davantage de crédibilité à sa coopération avec l'administration française, une telle situation ne manquait pas d'intérêt, et en aurait tout particulièrement lorsque viendrait, comme on pouvait l'attendre, un changement de pouvoir et que s'amorcerait l'évacuation de l'armée française.

Lettre $n^{\circ} 51$ de Murâd bey à Donzelot en date du 10 muharram 1215/2 juin 1800

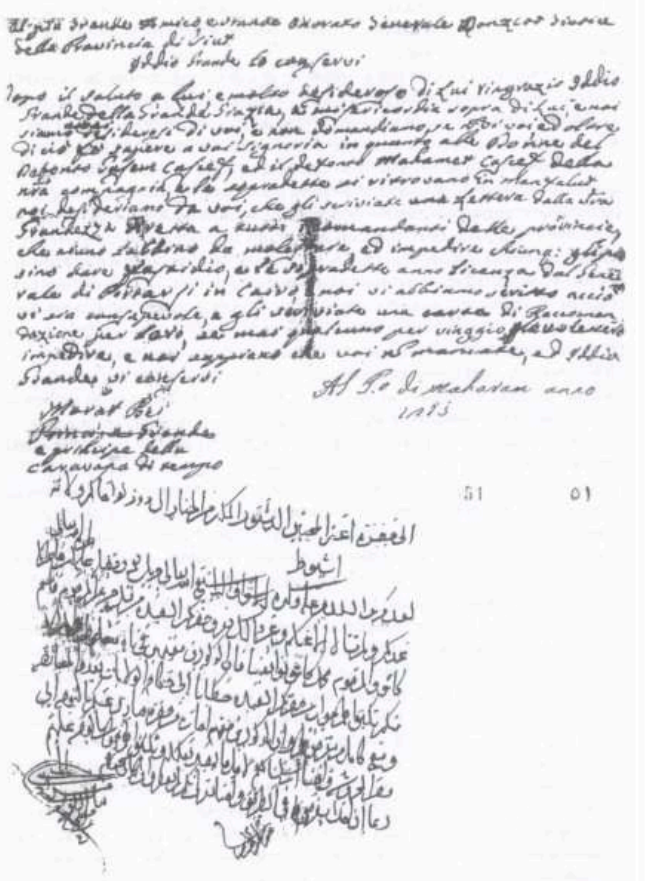

Le contrôle des mouvements des Mamelouks entre les deux zones

La question du contrôle des déplacements des émirs mamelouks entre les deux zones occupe une place remarquablement importante dans les correspondances. Elle se trouva soulevée le jour où Murâd bey apprit qu'un grand nombre de Mamelouks se pressait vers Asyût et Manfalût sans son autorisation et à son insu. Pour l'émir du Sa'îd, le danger était qu'avec eux, ne lui échappent les rênes du pouvoir et sa politique d'union des forces mameloukes. S'il ne la traitait rapidement, l'affaire pouvait avoir des conséquences, non seulement sur sa légitimité à représenter l'ensemble des forces mameloukes, mais encore sur leur avenir politique. Aussi se dépêcha-t-il d'écrire une longue lettre à Donzelot l'exhortant à n'en intégrer aucun sans son accord préalable : «Ce que nous vous demandons, c'est que, s'il se présente dans vos villages de BasseÉgypte des Mamelouks ou des kushshâf, d'où qu'ils viennent, par le fleuve ou le désert, sans une lettre de nous, vous les renvoyiez et les laissiez se présenter à nous, ou que vous les reteniez et que vous nous le fassiez savoir ». Conscient que ses exigences pouvaient heurter l'état-major français et avoir des conséquences négatives sur leurs relations, il justifie sa demande par son désir d'accroître la sécurité : "Car notre désir est de contrôler les Mamelouks (ghuzz) pour préserver la faveur dont nous jouissons 
auprès de la République.» En réalité, il redoutait surtout que les Mamelouks ne cherchassent à fuir pour rejoindre les rangs ennemis en Syrie ${ }^{62}$.

De tout cela, il résulta que les deux parties se mirent d'accord pour organiser le contrôle du mouvement des Mamelouks dans les deux zones. Murâd bey suggéra que le contrôle se fasse au moyen de ce qu'il appelait un laissez-passer (ijâza), qu'il délivrerait lui-même, et sur lequel il apposerait son sceau, qui était connu des Français. Il insistait également sur le rôle des "gendarmes " (multazimû al-admâk) dans la surveillance et la poursuite, qu'il s'agisse des responsables de la sécurité sur le Nil ou de leurs homologues sur les routes, faisant valoir qu'«ils ne devaient plus laisser un seul Mamelouk sans un permis de nous $»^{63}$ et que, "au nom de l'ordre ", il ne convenait pas que l'administration accordât de laissez-passer aux Mamelouks en fuite, qui s'étaient établis à Asyût ou dans toute autre région placée sous autorité française. Le but, évidemment, était de faire sentir à Donzelot la gravité de la question, tout en se dégageant de toute responsabilité au cas où la conduite des Mamelouks, contrairement à la sienne, causerait quelque désordre. Par ce dernier point, Murâd bey réaffirmait qu'il se portait, en revanche, garant des autres Mamelouks ${ }^{64}$.

Pour prouver à l'état-major qu'il contrôlait tous ses hommes et avait la situation bien en main, il s'attacha dans le même temps à empêcher toute correspondance personnelle entre ses Mamelouks et Donzelot. Il barrait la route à tous ceux qui auraient voulu trouver une brèche à l'intérieur de ses propres rangs ${ }^{65}$. Il est vrai que le contrôle des Mamelouks par l'entremise de Murâd était, sans aucun doute, le seul moyen de garantir la paix au mieux des intérêts de chacun. Le laissez-passer (ijâza ou tadhkara murâdiyya) était le plus sûr moyen de contrôle de la coopération des deux parties, surtout par l'usage que Murâd en faisait : il ne se contentait pas d'établir le document - qui consistait en une recommandation portant le nom de son porteur -, mais il l'appuyait en écrivant à Donzelot une lettre reprenant les mêmes informations, pour qu'il soit informé des déplacements de tel ou tel émir. S'il s'agissait de franchir la frontière entre les deux zones de la Haute-Égypte, il l'indiquait et écrivait aux généraux des provinces concernées pour qu'ils leur facilitent le passage, sans embarras ni difficulté. Si le but était Le Caire, il devait écrire à l'état-major pour obtenir du général en chef un laissez-passer similaire. Il mettait également Donzelot au courant, pour qu'il l'appuie de ses recommandations aux officiers commandant dans les provinces et aux responsables du contrôle des laissez-passer ${ }^{66}$. Murâd bey était bien conscient de l'importance de l'attribution de son laissez-passer et de la crédibilité qui devait lui être attachée, s'il voulait s'assurer le ralliement de tous. Son inquiétude sur l'obligation faite par les Français à tous les Mamelouks de payer intégralement les octrois, alors que les porteurs de permis en étaient, pour partie, exemptés, est sans doute une autre preuve de sa détermination à respecter ses promesses et les engagements qu'il avait pris envers les siens. Il écartait ainsi le risque de les voir perdre leur confiance dans le laissez-passer et se soulever. Dans le même temps, il pouvait assurer Donzelot qu'il n'accordait de permis qu'aux plus fidèles de ses hommes ${ }^{67}$.

Ces attributions exclusives et tous les privilèges que la politique de l'émir du Sa'îd avait mis en place, furent un élément important dans le ralliement des Mamelouks à son autorité. Pour les Français, dans le même temps, elles garantissaient que ceux qui l'avaient quitté, ou plus exactement ceux qui se trouvaient hors des principes réglant les relations de Murâd avec eux, n'auraient pas la possibilité de tirer avantage du renforcement de leur alliance. Les laissez-passer délivrés par Murâd bey étaient une 
pièce importante du dispositif régulant les rapports des Français avec les gens de l'émir du Sa'îd. Ils devinrent un moyen politique d'établir des liens fondés sur une confiance véritable. Il existe assurément un lien entre la fourniture aux Français de quantités importantes de vivres - d'un coût total de 86500 paras $^{68}$-, par l'émir Muhammad Kâshif après la signature du traité avec le général Friand (adjudant du général en chef Menou) et les très nombreuses recommandations et laissez-passer que son maître Murâd écrivit en sa faveur. Les laissez-passer étaient bien un instrument de contact continu entre les Mamelouks et les Français ${ }^{69}$.

Le désir de Murâd de tenir le général Donzelot informé de tous les déplacements des Mamelouks, y compris les siens ${ }^{70}$, renseigne aussi sur l'extension des pouvoirs que ce général avait obtenus, depuis que l'état-major l'avait chargé de la surveillance de la principauté de Girgâ. Mais si les déplacements des Mamelouks se déroulaient conformément aux mesures de contrôle, les déplacements des Français entre les deux zones n'amenaient, eux, aucune remarque, personne n'ayant à franchir les frontières d'Asyût, hors des missions officielles pour lesquelles Donzelot appliquait les mêmes mesures que Murâd bey : il l'informait du nom du responsable, de sa qualité et de sa mission, des recommandations qu'il lui adressait, pour aplanir les difficultés auxquelles ils auraient à faire face ${ }^{71}$. Seuls faisaient exception les déserteurs français installés à Girgâ. Donzelot chercha en vain à les faire revenir. Il écrivit à Murâd bey à leur sujet. Craignant que Donzelot ne pense qu'il cherchait à les attirer à lui, ce dernier s'empressa de l'assurer qu'il ne faisait rien pour les retenir et que, si l'amnistie que leur avait accordée l'administration militaire les avait bien incités à quitter Girgâ, ils n'avaient cependant pas tardé à faire demi-tour, en dépit des Mamelouks et des kushshâf que lui, Murâd, avait mis à leur disposition pour assurer leur sécurité ${ }^{72}$. La lettre de Donzelot à Murâd fournit certains détails sur la situation de ces soldats à Girgâ : ils vivent loin de l'armée de Murâd, « ils sont vêtus à la manière des paysans, ils ne mangent pas avec les Mamelouks, ils ne montent pas à cheval et ne portent pas d'armes $»^{73}$. Cette situation anormale irritait l'état-major français, comme en témoigne l'opiniâtreté de Donzelot à trouver un moyen de les contraindre à quitter $\operatorname{Girg}^{74}$. Le problème des déserteurs se posait, en réalité, dans les deux camps, mamelouk aussi bien que français. Son apparition, dans les premiers mois qui suivirent la signature du traité (entre juillet et décembre 1800), indique que la plus grande des confusions avait semblablement envahi les deux camps, mêmes si les mobiles en étaient différents. C'est probablement la disette qui sévissait dans la Haute-Égypte qui a poussé les soldats, de part et d'autre, à pénétrer dans le camp ennemi, pour assurer leur survie.

À en juger par les correspondances, l'administration mamelouke de la principauté de Girgâ apparaît ainsi conforme au système traditionnel: elle s'appuyait sur la personnalité de l'émir mamelouk qui gouvernait la province. C'est à lui qu'il incombait de répartir entre les émirs, sandjak-beys et kushshâf, selon les unités administratives, les concessions fiscales (kushûfiyyât) dont étaient constituées les provinces. La principauté, pour autant, n'était pas totalement indépendante. L'obligation faite à Murâd de payer l'impôt foncier (mirî) ; le fait que Donzelot soit gouverneur d'Asyût et de Minyâ, mais avec des pouvoirs administratifs qui s'étendaient jusqu'à l'intérieur même de la principauté mamelouke ; l'extension de la nouvelle organisation judiciaire à tous les tribunaux de Girgấ ${ }^{75}$, dans tous les domaines où la loi musulmane (sharîa) s'appliquait : tout cela constitue autant de preuves de ce que la principauté de Girgâ restait dans le giron de l'administration centrale, et par là-même, du commandement de l'expédition. Pour les Mamelouks, l'affaire ne dépassait pas le cadre d'une simple 
autonomie. Ces restrictions apportées à leur pouvoir ne les gênaient guère, du reste, car ils ne faisaient pas du statut qui leur était concédé le but ultime de leur action politique : il ne formait qu'une étape nécessaire pour retrouver leur unité76 et les remettre en état de prendre part à une lutte où il n'y avait de place ni pour les faibles, ni pour ceux dont les forces étaient éparpillées.

Les échanges entre Girgâ et les régions sous autorité française

Les correspondances fournissent également des indications précieuses sur l'économie de la principauté. Il est possible de distinguer ce qui concerne la nature du rôle joué par Murâd bey dans la levée de l'impôt et son rôle dans la résolution des problèmes économiques existant dans les provinces de Girgâ et d'Asyût.

Murâd Bey et la levée de l'impôt foncier (mîrî)

31 Les Français, en raison des événements politiques et militaires de l'hiver $1800{ }^{76}$, n'avaient pas été en mesure de percevoir les taxes sur les récoltes d'hiver, qui constituaient l'essentiel du revenu fiscal de l'année. La signature du traité avec Murâd bey devait leur fournir l'occasion de réorganiser la perception de l'impôt. Kléber attacha au traité une clause qui faisait obligation à Murâd bey de réquisitionner tous les impôts, en nature et en espèces, que Darwîsh pacha ${ }^{77}$ avait prélevés dans la HauteÉgypte durant les mois de février et mars pour les envoyer directement au Caire, de même qu'il le chargeait d'assister le mu'allim Yacqûb dans la mise en recouvrement du solde que l'on n'avait pu encore percevoir. Cela n'allait pas sans une définition stricte des responsabilités de chacun. Tandis que le mu'allim Yacqûb devait dresser l'inventaire de toutes les taxes, en grains et en espèces, imposées à chaque village ou commune et désigner les entrepôts (shûna) où elles seraient stockées, Murâd bey devait prendre toutes les mesures nécessaires pour les recouvrer et organiser leur achemiment intégral au Caire, puisque, aussi bien, il n'avait pas le droit d'agir pour son profit personnel ou celui des siens, dans les régions comprises entre Gîza et Asyût: aux termes du traité, il ne pouvait lever l'impôt pour son propre compte que dans la région placée sous son autorité, à savoir la province de Girgầ ${ }^{78}$.

Immédiatement après la signature, le 5 avril 1800, Murâd bey se mit donc en route vers la Haute-Égypte. En moins de trois mois, il fut en mesure de réquisitionner ce qu'avait réuni Darwîsh pacha et rejoignit Le Caire, le 1er mai ${ }^{79}$. Il y déploya un beau zèle avec ses gens, ses kushshâf et ses sandjak-beys qui, s'étant répandus de tous côtés, collectaient les grains et l'argent qu'ils envoyaient sur les bords du Nil, pour que là des bateaux, réquisitionnés par Murâd bey, en assurent le transport jusqu'aux entrepôts à grains. Pour chaque village ou groupe de villages - et même dans les situations particulières où l'impôt (kharâj) était perçu sur les terres d'un agent des Français -, Murâd prenait le soin d'écrire à Donzelot pour l'informer qu'il avait mené l'affaire à bien ${ }^{80}$. De cette façon, et contrairement à ce qui, à leur grand détriment avait été jusque-là de règle, les Français purent obtenir l'impôt sur les cultures d'hiver sans le moindre affrontement avec les paysans. Aucun village, en effet, n'aurait payé les taxes, s'il n'y avait eu, pour l'y contraindre, un détachement militaire important ${ }^{81}$. L'annonce du traité de paix signé avec Murâd fut donc un événement majeur pour rétablir la stabilité économique en Haute-Égypte. La présence d'émirs, de kushshâf et de sandjak-beys acquis à Murâd bey aux côtés de chaque détachement militaire français était une garantie pour obtenir la confiance des contribuables, paysans ou fermiers généraux (multazim) qui acceptaient de payer l'impôt intégralement, assurés qu'on ne viendrait pas le leur demander une seconde fois, comme c'était le cas auparavant. 
Murâd bey tenait à confirmer à Donzelot qu'il avait intégralement respecté ses engagements, que pas un seul village, pas une seule circonscription n'avait osé refuser de payer le mîrî: «Et si Dieu veut - qu'Il soit exalté -, tant que vous et nous serons là, personne ne pourra plus payer ce qu'il doit en retard. $»^{82}$ L'administration française, du reste, ne pouvait guère douter du pouvoir de cet émir et de son étendue, ni de l'aura dont il jouissait auprès des populations. Ses représentants avaient pu, lors de missions, voir les cheikhs des villages de Haute-Égypte l'accueillir en masse et lui offrir des sommes importantes en guise de cadeau de bienvenue, quand il était venu s'installer à Girgâa $\hat{a}^{83}$. Ce fut sans doute aussi ce qui disposa l'administration française à nommer, pour faciliter la levée de l'impôt et assurer la paix et la stabilité dans les campagnes, des kushshâf, des sandjak-beys, ou des Mamelouks de Murâd bey à la tête des circonscriptions fiscales des régions placées sous son autorité.

Les correspondances font également la lumière sur le rôle de Murâd bey dans les opérations cadastrales. Avec la crue de l'été 1800, puis la décrue et les semailles, l'administration de l'expédition le chargea de prendre toute mesure nécessaire pour mener à bien, pour chaque village et chaque commune, les opérations d'arpentage des terres irriguées et ensemencées en grains, pour pouvoir définir la valeur de l'impôt. Ces opérations d'arpentage, on le sait, étaient toujours des plus difficiles et nécessitaient la présence d'une force militaire qui accompagnait les arpenteurs pour leur permettre d'opérer correctement. Murâd bey montra un vif intérêt pour l'affaire, au point de lui consacrer la moitié de ses forces ( 2000 Mamelouks) ${ }^{84}$, avec chevaux et chameaux. Il informa Donzelot de ses préparatifs et lui manda qu'il pouvait envoyer les arpenteurs chargés par l'administration fiscale d'établir un mémoire détaillé et précis, où seraient consignées toutes les sommes dues au Trésor français ${ }^{85}$. Murâd bey étant, d'autre part, seul responsable de la perception des impôts sur les terres de mainmorte (waqf) de Dashîsha, dont certaines se trouvaient hors de la région placée sous son autorité, comme la ville d'Abû Tîg qui relevait de la province d'Asyût, la même méthode fut appliquée: tandis que Murâd bey envoyait «un chargé d'affaires ('âmil) et un arpenteur », Donzelot dut fournir une colonne conduite par un officier français, pour garantir la bonne exécution de l'arpentage et prévenir toute négligence ou perturbation dans l'évaluation ou la perception de l'impôt. Murâd bey alla, du reste, jusqu'à demander à Donzelot des détails sur le déroulement des opérations sur ces terres waqf, pour qu'il soit tranquille sur la précision des mesures et des résultats qui lui parvenaient ${ }^{86}$. Au moment des récoltes, au début du mois d'août, il chargea l'un de ses kushshâf d'en recouvrer l'impôt. Dans le même souci d'éviter toute difficulté, que ce soit avec les responsables français du fisc ou avec les paysans qui redoutaient toujours qu'on ne les trompe en exigeant d'eux deux fois le paiement de l'impôt, il demanda à Donzelot d'établir un laissez-passer pour un de ses agents, Salîm kâshif d'Asyût, chargé de recouvrer les impôts de cette ville ${ }^{87}$. De son côté, le commandement français ne désirait pas retirer l'administration des waqf de Dashîsha à Murâd bey, en raison de la nature religieuse particulière de cette institution dont le revenu était consacré aux villes saintes. Les placer sous autorité française eût entraîné trop de problèmes, au moment où elle s'efforçait d'établir des liens commerciaux avec les dignitaires du $H_{e d j a z}{ }^{88}$. Elle était plutôt d'avis d'aider Murâd dans le recouvrement des impôts, qu'il envoyait par le port de Qusayr.

Par ailleurs, c'est surtout pour l'acheminement de l'impôt que Murâd bey rendit les plus grands services aux Français. Après les récoltes et la collecte des taxes en nature, 
on eut besoin de bateaux pour transporter les grains vers les entrepôts du Caire. Les Français, qui n'avaient que peu de bateaux car ils en avaient brûlé un grand nombre pour récupérer le bois comme combustible ou bois de chauffage ${ }^{89}$, se tournèrent vers Murâd bey pour lui demander de rassembler tous les bateaux en sa possession. Girgâ était célèbre, en effet, pour ses chantiers navals ${ }^{90}$ et, notamment, la construction de grands chalands spécialisés dans le transport des grains et des marchandises pondéreuses. Murâd, aussitôt, envoya ses agents parcourir sa province, à la recherche de bateaux qu'ils envoyaient directement à Asyût ${ }^{91}$, pour que le général Donzelot procède ensuite à leur distribution dans les diverses provinces de la Haute-Égypte. Sans doute l'engagement pris, du côté français, de payer intégralement le prix de la location aux propriétaires des bateaux fut-il un encouragement efficace ${ }^{92}$. Et puis Murâd bey avait exigé de Donzelot qu'une fois achevé le transport de l'impôt, on lui renvoyât vers Girgâ des bateaux qui rendaient de trop nombreux services pour qu'il pût y renoncer ${ }^{93}$. Les relations entre Girgâ et Asyût

Les relations économiques entre les deux zones, mamelouke et française, suscitaient aussi des problèmes sur lesquels les correspondances apportent bien des éclaircissements. L'agression commise par les hommes de Mahmûd b. Wâfî contre une caravane commerciale que conduisait al-Bashîr, fils du Sultan de Dongola, en est un bon exemple. Les voleurs capturèrent 132 personnes, s'emparèrent de leur argent, de leurs chameaux et de leur bétail, ainsi que de toutes les marchandises qu'ils apportaient du Soudan ${ }^{94}$. Les caravanes du Darfour et du Sennar apportaient à Murâd un revenu conséquent, puisqu'elles acquittaient des droits de douane à la frontière d'Isnâ avant de traverser la province de Girgâ en direction d'Asyût. Elles fournissaient, en outre, des marchandises précieuses: du bois de charpente pour les bateaux, des esclaves qui pouvaient être intégrés dans les rangs des forces mameloukes et qui étaient d'autant plus précieux que la Sublime Porte avait établi un embargo sur l'importation des esclaves blancs, de la poussière d'or qui entrait dans la fabrication de la monnaie, etc. ${ }^{95}$ On pouvait donc s'attendre à ce que Murâd bey n'épargnât aucun effort pour régler l'affaire, non seulement en raison des pertes en hommes et en biens, mais aussi parce qu'il devait empêcher que ne se reproduise un incident qui était de nature à ruiner le commerce caravanier. Comme cette agression ne menaçait pas seulement l'économie de Girgâ mais qu'elle nuisait aussi à la zone française, Murâd bey préféra ne pas affronter directement les hommes d'Ibn Wâfî : il s'en remit à Donzelot, au prétexte que leur base principale se trouvait dans la province d'Asyût. Dépêché par lui à Asyût, le prince de Dongola, al-Bashîr, donna à Donzelot tous les détails de l'agression ${ }^{96}$. Donzelot montra un vif intérêt pour l'affaire et manda aussitôt à Muhammad b. Wâfî de libérer les captifs et de restituer le butin, lui faisant valoir qu'une telle agression était de nature à mettre un terme à toute relation entre sa tribu et les Français. Ce dernier se dépêcha de faire machine arrière. Il promit à Donzelot de régler toute l'affaire : « Nous avons pris connaissance de votre lettre et de ce que vous nous demandez. Nous ne voulons pas de discorde, car votre situation et la nôtre, c'est tout un. " Il lui demanda de faire savoir à Bashîr que son bien lui serait rendu sous deux jours, le temps de le reprendre à ceux qui avaient participé à l'agression ${ }^{97}$.

Le fait est que cet incident avait provoqué les craintes du sultan du Darfour qui envoya en délégation deux émissaires à lui à Asyût. Ils devaient discuter avec les responsables français des mesures à prendre pour assurer la sécurité des caravanes et empêcher toute récidive. Donzelot leur fit le meilleur accueil et informa Menou qu'il enverrait des présents au Sultan pour ramener la confiance et l'amitié et relancer le commerce. 
Menou soutint cette mesure par un ordre du jour exemptant des taxes douanières perçues à Asyût toute une caravane arrivée en septembre $1800{ }^{98}$. La coïncidence des intérêts de Murâd bey avec ceux des Français les conduisit ainsi à accroitre leur protection sur les deux caravanes du Darfour et du Sennar. Cette affaire reflète assez bien la coopération des deux parties et leur manière de traiter des problèmes que leur politique leur commandait de ne pas négliger par crainte de leurs retombées économiques ${ }^{99}$.

Une autre illustration en est fournie par l'affaire de la douane d'Asyût. Kléber l'avait créée en juin 1800, soit deux mois après la signature du traité. Toutes les marchandises et denrées étaient inspectées et soumises aux droits d'octroi ${ }^{100}$. Située à la frontière entre la zone placée sous l'autorité mamelouke et les provinces placées sous commandement français, cette douane était une véritable barrière. Les taxes prévues par Kléber étaient fort lourdes, dans le but de déplacer le commerce de la mer Rouge de Qusayr, dont les taxes douanières revenaient à Murâd, à Suez ${ }^{101}$ qui était sous contrôle français. Il semble toutefois que l'état-major français, dans un souci d'apaisement, ait accordé à Murâd un privilège qui lui permettait d'obtenir pour les siens un allégement d'une partie des taxes imposées. Mais de trop nombreux Mamelouks prétendirent être des gens (ra'iyya) de Murâd bey, et devant le désordre ainsi créé, les responsables des douanes décidèrent d'imposer des taxes complètes sur toute marchandise pesée. Murâd bey en informa Donzelot en protestant de son innocence ${ }^{102}$ : «Nous n'avons accordé notre protection (himâya) qu'à nos émirs, sandjak-beys et kushshâf, et nous ne l'avons jamais fait sans en avoir préalablement informé votre Seigneurie; en dehors de nos hommes [awlâd, littéralement "enfant »] nous n'accordons de billet de protection à personne, et nous ne saurions vouloir d'aucune tromperie. »

Murâd bey avait déjà suggéré de régler la question par le moyen d'un billet (tadhkara) indiquant l'objet de la "protection", le nom du porteur et portant son cachet. Cependant le contrôleur fluvial (wakîl al-bahr) à la douane refusa de prendre ceux qu'il émettait. Pour ramener l'affaire à son état premier, Murâd bey utilisa - comme à son habitude dans les affaires délicates -, une langue pleine de douceur: "Si le billet, en date du tant, que nous donnons à l'un des nôtres - émir sandjak-bey ou kâshif à l'exclusion de tout autre -, vous convient, alors nous lui donnons le billet que voici ; s'il ne vous convient pas, faites-le nous savoir pour que nous agissions en conséquence. $»^{103}$ En dépit de ces bonnes manières, il semble toutefois que le privilège de réduire les droits de douanes pour ses proches lui fut retiré ${ }^{104}$. Mais plus que tout, ce qui irritait Murâd c'étaient les façons de faire des inspecteurs chargés de la surveillance. Il s'en plaignit à Donzelot, auquel il demanda que le contrôleur fluvial veuille bien désormais se contenter de consulter la liste des marchandises dressée par le peseur-juré (qabbânî), sans exiger que l'on décharge le bateau ou que l'on repèse le chargement ${ }^{105}$.

Les nombreux services rendus par Murâd bey, qui lui avaient gagné une totale confiance auprès des Français, lui valurent ainsi d'obtenir des autorités le rétablissement de l'exemption, pour lui-même et les gens de sa maison, au-delà d'un poids défini chaque année ${ }^{106}$. La lettre numéro 102 exprime la gratitude de Murâd bey pour ce privilège : "Voici la liste relative aux douanes qui vous donne le détail des grains et autres denrées pour le poids convenu annuellement. Dieu - qu'Il soit exalté ! -, accroisse votre bien, nous en formons le vœu et bien plus encore. ${ }^{107}$ De toute évidence, Murâd bey était parfaitement conscient des efforts que déployait Donzelot pour aplanir les difficultés et régler les problèmes qui surgissaient à tout moment. 
Aussi chantait-il ses louanges, en des termes où les marques de tendresse le disputaient à celles du respect, dans toutes ses correspondances, et en particulier dans celles relatives à cette affaire de la douane d'Asyût ${ }^{108}$.

Lettre $\mathrm{n}^{\circ} 17$ de Donzelot à Murâd bey

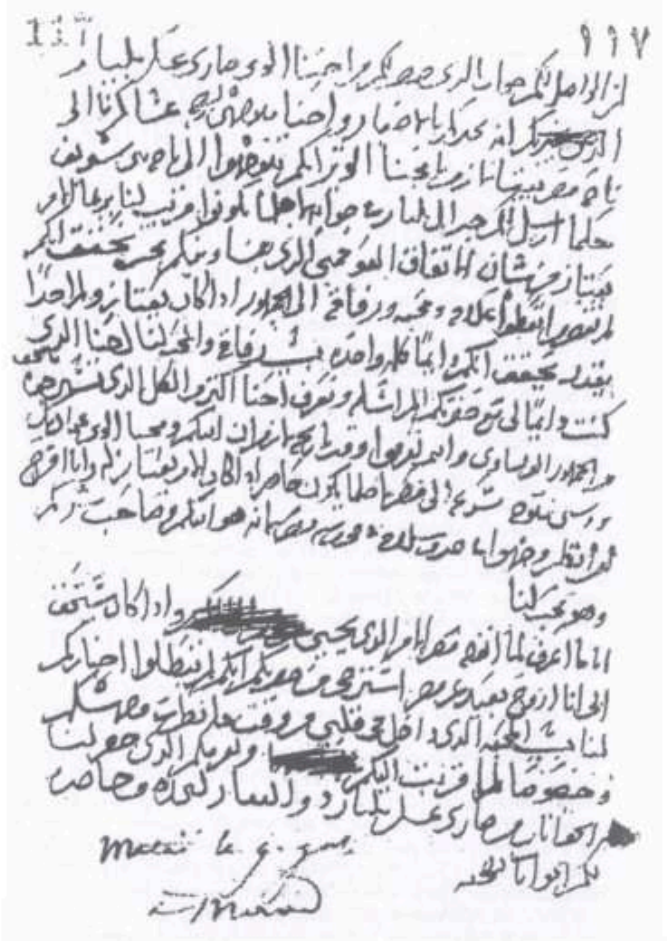

Les correspondances de Murâd bey forment donc une source de première importance pour l'étude de la principauté de Girgâ au début du XIX siècle, notamment pour la connaissance de son organisation administrative, encore proche du système mamelouk antérieur à l'expédition. Elles confirment qu'elle ne formait pas pour autant une entité indépendante et restait liée à l'autorité française, qu'elle n'était pas isolée des provinces voisines de la Haute-Égypte, d'Asyût et de Minyâ notamment, placées sous le commandement du général Donzelot, lequel, en tant qu'inspecteur général jouissant de vastes pouvoirs de surveillance, fut le principal gestionnaire des relations francomameloukes. Des liens particuliers l'unissaient à Murâd bey, qui ont fourni une base solide pour la stabilité, la paix et la consolidation des relations entre les deux camps.

Murâd bey, de son côté, se souciait moins d'accroître son autonomie que de saisir l'occasion de rétablir l'unité des rangs mamelouks, dans une région placée à l'abri des zones de combats et qui était l'une des plus des riches de Haute-Égypte. Il pouvait ainsi faire venir tous les Mamelouks de Syrie et les armer, dès leur arrivée à Girgâ. Tel était bien le fond de la pensée politique de ce chef mamelouk. Son décès prématuré, sans qu'il eût de successeur, empêcha l'achèvement d'une politique dont il avait tracé les grandes lignes: sa mort brisa l'unité des rangs mamelouks et en précipita l'émiettement et la dispersion sans recours ${ }^{109}$. Ses correspondances constituent aussi un matériau essentiel pour la réévaluation de sa biographie, en particulier pour la période de l'expédition. Elles confirment qu'il avait bien un projet politique, qu'il possédait un langage plein de calme, grâce auquel il maîtrisait ses relations avec autrui, qu'il se 
distinguait par sa douceur en matière politique, ce qu'il lui permettait de supporter tous les refus faits, du côté français, à ses demandes, de répondre favorablement à tous les ordres ou renseignements qu'on lui adressait, tant que cela ne l'empêchait pas de poursuivre la réalisation de son projet politique. Enfin, elles donnent de sa personnalité une image bien différente de celles que les autres sources en proposent - Gabartî en particulier -, sur lequel ont été fondées jusque-là la plupart de ses biographies. L'histoire de Murâd bey est probablement à réécrire, car il semble bien que le regard qu'on a porté sur lui n'était pas neutre et qu'on ait été largement prévenu contre lui ${ }^{110}$.

\section{NOTES}

1.Nabîl al-Tûkhî, La Haute-Égypte au temps de l'expédition, 1798-1801 , Le Caire, al-Hay’a al-'âmma li-l-kitâb, 1997, p. 233-235.

2.Voir par exemple, J.-L. Reynier, State of Egypt After the Battle of Héliopolis, translated from French, De l'Égypte après la bataille d'Héliopolis, London, 1802, p. 210-216 ; L. Reybaud, Histoire scientifique et militaire de l'expédition française en Égypte, Paris, 1830-1836, t. VIII, p. 107-111 ; P. Martin, Histoire de l'expédition française en Égypte (1798-1801), Paris, 1815, t. II, p. 167-173.

3.Le général Donzelot est l'un des plus éminents généraux français envoyés en HauteÉgypte. Adjudant-général, il fut chargé du commandement d'un bataillon dans l'armée d'Orient. Nommé général de brigade en 1799, il était gouverneur de Qusayr durant la période des combats avec Murâd. Après la signature du traité de paix, il fut nommé gouverneur de la province (wilâya) d'Asyût et de Minyâ, pour être finalement élevé au grade de général de division en 1807. Voir Jean Bourguignon, Souvenirs historiques, Musée de l'Orangerie, 1938, p. 96.

4.Napoléon Ier et son temps, s. 1. n. d., p. 70-74. Il semble que l'index des documents relatifs à l'expédition conservés à la Bibliothèque centrale de l'université, dressé par Ahmad 'Abd al-Râziq Ahmad, n'est qu'une traduction de certains éléments de l'index français. Assez curieusement, l'auteur a, du reste, reconnu son emprunt, en signant de son nom chacun des paragraphes retenus. Il a simplement reclassé les documents en sept ensembles, chaque ensemble regroupant un certain nombre de dossiers, sans donner les raisons de cette classification. Son index a été publié dans les Actes du colloque consacré à 'Abd al-Rahmân al-Gabartî publiés par al-Hay'a al-'âmma li-l-kitâb, Le Caire, 1976, p. 597-620.

5.Ibid., p. 74 .

6.Je remercie Ramadân al-Khûlî qui disposait d'une photocopie des lettres et qui nous a permis de les consulter et d'en faire une copie. Ces neuf lettres ne figurent pas dans l'ensemble original.

7.Traduction de la lettre de Murâd bey au général Damas. Dâr al-wathâ'iq al-qawmiya (Archives nationales du Caire), Documents de l'expédition française, $n^{\circ} 33$, carton $n^{\circ} 13$, B6 60, document 14867. 
8.Comme vient le confirmer la date de la lettre que Murâd bey adressa au général Donzelot pour déplorer l'assassinat du général en chef Kléber. Cette lettre porte le $\mathrm{n}^{\circ}$ 60 , en date du 1er safar 1215/24 juin 1800 .

9.Traduction d'une lettre de Murâd bey au général Donzelot, le 3 août 1800, Dâr alwathâ'iq al-qawmiyya, Documents de l'expédition française, $n^{\circ} 25$, dossier 12. 10.Le nombre de lettres adressées par des émirs à Donzelot est de 6 , pour 41 lettres de Murâd bey, 3 de Donzelot, 1 de Mahmûd b. Wâfî, cheikh de la tribu des Banû Wâfî, et enfin une plainte adressée par la population de Tahtâ au général Donzelot.

11.Napoléon Ier et son temps, p. 74.

12.Murâd bey est mort de la peste le 4 dhû al-hijja 1215/18 avril 1801, et la lettre portant le $\mathrm{n}^{\circ} 112$ a donc été écrite 11 jours avant son décès. Voir 'Abd al-Rahmân alGabartî, Mazhar al-taqdîs bi-dhahâb dawlat al-faransîs, édition de 'Abd al-Râziq cîsâ et 'Imâd Hilâl, Le Caire, al-'arabî li-l-nashr wa-l-tawzî', 1998, t. II, p. 476.

13.L'index français des fonds de la Bibliothèque centrale de l'université du Caire signale l'existence de 7 registres de lettres émanant de Donzelot, adressées soit au général Dizier, soit au général en chef de l'expédition, soit encore à Murâd bey et qu'ils comptent environ 450 feuilles. Et bien qu'ils couvrent la période qui va du 7 mai 1799 au 25 mars 1801, ils ne comportent, en ce qui concerne les lettres adressées à Murâd bey, que celles de la période qui précède sa reddition aux Français. Malheureusement, ces registres ne figurent plus actuellement parmi les documents de la Bibliothèque centrale. Cf. Napoléon Ier et son temps, p. 68.

14.Ce sont les lettres $n^{\circ} 116,117,118$.

15.Voir, par exemple, les lettres $n^{\circ} 44,58,72,73,104$.

16.Ce sont les lettres $n^{\circ} 75,76,79,80,82$.

17.Napoléon Ier et son temps, p. 74 .

18.Les documents de l'expédition à la Bibliothèque centrale de l'université du Caire offrent de nombreux exemples de cette sorte de papier, où le filigrane est constitué par l'emblème de la République française et qui symbolise la France par une jeune fille tenant d'une main un sceptre et de l'autre des faisceaux, parfois entourée d'une guirlande de laurier.

19.Ainsi par exemple les lettres $n^{\circ} 64,66,72$ et 73, portant le cachet de Murâd bey, conservent les deux traductions intégrales italienne et française ; les originaux des traductions portent, pour l'italien, les $n^{\circ} 120,122$, et 124 , et, pour le français, les $n^{\circ} 119$, 121 et 123 .

20.Barthélémy et Husayn al-Zântalî (le «Zantiote ») en sont deux exemples typiques ; tous deux d'origine grecque, maîtrisant quatre langues, dont l'arabe et l'italien, ils obtinrent les faveurs des Français aussi bien que des Mamelouks. Tandis que le premier travaillait au service des Français - il obtint le rang de général et fut l'émissaire de Kléber auprès de Murâd bey lors des préliminaires de paix -, le second se trouvait au service de Murâd bey, comme commandant d'artillerie, peu avant l'arrivée de l'expédition. Il fut le représentant de Murâd au moment de la rédaction des articles du traité. Élevé ensuite au rang de sandjak-bey, il devint le lieutenant de Murâd auprès de l'administration française au Caire. Voir Nicolas Turc, Dhikr tamallukjumhûr alfaransâwiyya al-aqtâr al-misriyya wa-l-bilâd al-shâmiyya, édition de Yâsîn Suwayd, Beyrouth, Dâr al-Fârâbî, 1990, p. 133-135.

21.Comparer le texte de la lettre $n^{\circ} 109$, en date du 18 sha'bân 1215/4 janvier 1801 avec le texte de la traduction, traduction de la lettre écrite par Murâd Bey au général 
Donzelot le 4 janvier 1801, Dâr al-wathâ'iq al-qawmiyya, Documents de l'expédition française, carton $\mathrm{n}^{\circ} 41$, dossier 2, B6 61.

22.Lettres de Donzelot à Murâd bey n 116,117 et 118 .

23.Dans une lettre à Donzelot, Murâd bey fait savoir qu'il a envoyé un de ses agents en Syrie (et que Kléber qui se trouvait encore au Caire pendant le mois d'avril en était informé) pour le tenir au courant des nouvelles, et qu'il leur rapporterait tout ce qu'il a obtenu comme renseignements là-bas. Voir lettre $n^{\circ} 54$, en date du 14 muharram 1215/7 juin 1800 .

24.Lettre de Murâd Bey à Donzelot, $\mathrm{n}^{\circ}$ 128, en date du 4 safar 1215/27 juin 1800 faisant état des deux lettres de Ibrâhîm bey et Hasan bey al-Jiddâwî que Murâd envoya à Donzelot : lettre $\mathrm{n}^{\circ} 99$, en date du 22 rajab 1215/9 décembre 1800 et lettre ${ }^{\circ} 100$, en date du 2 sha'bân 1215/19 décembre 1800 .

25.Le général Damas au général Donzelot, le 17 floréal, an VIII (4 mai 1800), Napoléon Ier et son temps, p. 104.

26.Le général en chef Kléber au général Donzelot, le 11 prairial an VIII (31 mai 1800), dans Henry Laurens, Kléber en Égypte, 1798-1800, 4 vol., Le Caire, IFAO, 1995, t. IV, p. 940. 27.Lettre de Murâd bey à Donzelot, $n^{\circ} 50,1 \mathrm{er}$ muharram $1215 / 3$ juin 1800 . On notera que Murâd bey avait l'habitude de faire allusion, dans ses lettres, au contenu des lettres que Donzelot lui avait envoyées.

28.Ibidem.

29.Lettres de Murâd bey à Donzelot, $\mathrm{n}^{\circ} 60,64,89,91,101,102,105,113$. Ces lettres couvrent la période qui va de juin 1800 à février 1801.

30.Lettres de Murâd bey à Donzelot, $n^{\circ} 72$, en date du 26 safar 1215/19 juillet $1800 ; n^{\circ}$ 98, en date 21 rajab 1215/8 décembre 1800 .

31.Lettres de Murâd bey à Donzelot, $n^{\circ} 102$, en date du 12 sha'bân 1215/29 décembre 1800; n 104, en date du 29 sha'bân 1215/15 janvier 1801.

32.Lettres de Murâd bey à Donzelot, $n^{\circ}$ 54, en date du 14 muharram 1215/7 juin 1800.

Deux semaines plus tard, Donzelot lui confirme que les communications sont à nouveau régulières ; voir $\mathrm{n}^{\circ}$ 58, en date du 28 muharram 1215/21 juin 1800.

33.On trouve, par exemple, les noms de Murâd al-Mulâzim et de Dhû-l-Fiqâr katkhuda qui, sitôt qu'ils avaient remis les lettres du côté français à Murâd bey, retournaient à Asyût ou au Caire. Voir les lettres de Murâd bey à Donzelot $n^{\circ} 104$, en date du 29 sha'bân $1215 / 15$ janvier $1801 ; n^{\circ} 109$, en date du 18 sha'bân $1215 / 4$ janvier $1801 ; n^{\circ}$ 112, du 23 dhû al-qa'da 1215/7 avril 1801 ; et de Donzelot à Murâd bey, n 117, sans date.

34.Lettre de Murâd bey à Donzelot n 93 , en date du 21 jumâdâ II 1215/9 novembre 1800 ; voir aussi la lettre du général Donzelot au général en chef Menou, en date du 25 messidor an VIII/11 juillet 1800, publiée dans le supplément à l'étude de Nabîl al-Tûkhî, op. cit., annexe $\mathrm{n}^{\circ} 13, \mathrm{p} .379-381$.

35.Lettre de Murâd bey à Donzelot, $n^{\circ}$ 93, en date du 21 jumâdâ II 1215/9 novembre 1800. L'usage de ces « messages verbaux » était répandu parmi les Mamelouks. Les lettres de Murâd comportent de nombreuses indications de nouvelles d'ordre militaire reçues oralement de Syrie et rapportées en ces termes : « et cela nous l'avons appris par la langue ». Voir par exemple la lettre $\mathrm{n}^{\circ} 73$, en date du 29 safar 1215/22 juillet 1800. 36.Lettres de Murâd bey à Donzelot, $n^{\circ} 108$, du 15 shawwâl 1215/1er mars 1800 ; et $n^{\circ}$ 118 , sans date.

37.Ordre du jour du général en chef Kléber, le 28 fructidor an VII (14 septembre 1799), in Kléber en Égypte, t. III, p. 50-51. 
38.Nabîl al-Tûkhî, op. cit., p. 23. Le texte de la décision du 17 floréal an 8 (7 mai 1800) figure à l'annexe $\mathrm{n}^{\circ} 11$, p. 370 .

39.Village ancien du district de Sûhâg.

40.Traité avec Murâd bey, le 15 germinal an VIII (5 avril 1800), in Kléber en Égypte, t. IV, p. 803-806.

41. Napoléon Bonaparte, Correspondance de Napoléon 1er, publiée par ordre de l'Empereur Napoléon III, 32 vols, Paris, Henri Plon, 1858-70, t. IV, n² 2921, p. 295.

42.Al-Gabartî, op. cit., p. 397-398.

43.Ce sont les kushûfiyyât d'Asyût, d'Abû Tîg, Tamâ, Tahtâ, Akhmîm, Farshût, Bardîs, Hiw, Bahgûra, Qîna, Qûs, Isnâ, Ibrîm, Alwâh (Oasis). Cf. Layla 'Abd al-Latîf, al-Idâra fî misr fîl-'asr al-'uthmânî, Le Caire, Matbu'ât Gâmi'at 'Ayn Shams, 1978, p. 381.

44. Copie d'une lettre du mîr liwâ Murâd bey à 'Abdallah Menou, général en chef, $n^{\circ} 67$, en date du 15 safar 1215/8 juillet 1800 .

45.Ahmad Husayn al-Sâwî, al-Mu'allim Ya'qûb, bayn al-ustûra wa-l-haqîqa, Dâr al fikr li-ldirâsât wa-l-nashr wa-l-tawzî’, Le Caire, Silsilat Kitâb fikr, nº 9, 1986, p. 87.

46.Lettre de Murâd bey à Donzelot, $n^{\circ}$ 60, en date du 1er safar 1215/24 juin 1800 .

47.La lettre du général Donzelot au général en chef Menou en explique le contenu : « La réponse est entre vos mains, mon général, et je vous prie de décider de la suite à donner à ses demandes d'ajournement de la taxe du miri pour cette année et d'ajout de certains villages. " Le texte de la lettre est publié dans Nabîl al-Tûkhî, op. cit., annexe ${ }^{\circ}$ 14, p. 379-384.

48. H. Laurens, L'expédition d'Égypte, Bonaparte et l'islam, traduction Bashîr al-Sibâcî, Le Caire, Sînâ li-l-nashr, 1995, p 552-553 ; Nabîl al-Tûkhî, op. cit., p. 265.

49.D'après un rapport adressé par l'inspecteur des finances, M. Beausillage, au quartier général, sur les noms des villages de la province de Girgâ et les unités de mesure utilisées pour l'impôt en grains, il ressort que l'ensemble des contributions s'élevait à 304653 6/24 ardab. Voir État des contributions en grains des villages de la province de Girgé, rapport qu'on trouvera dans les documents relatifs à l'expédition à la Bibliothèque centrale, carton $n^{\circ} 196$, dossier $g$ VIII.

50.Lettre de Murâd bey à Donzelot, $n^{\circ}$ 94, en date du 23 jumâdâ I 1215/12 septembre 1800 .

51.Ibidem.

52.Lettres de Murâd bey à Donzelot $n^{\circ} 103$, en date du 23 sha'bân 1215/9 janvier 1801 ; lettre $n^{\circ} 104$, en date du 29 sha'bân 1215/15 janvier 1801.

53.G. Reynier, op. cit., p. 212-213.

54.Ahmad Husayn al-Sâwî, op. cit., p. 24.

55.Lettre de Murâd bey à Donzelot, n 76, en date du 15 rabî̀ I 1215/8 août 1800 .

56.Lettre de Murâd bey à Donzelot, $n^{\circ}$ 112, du 23 dhû al-qa'da 1215/7 août 1800 .

57.Ainsi, par exemple, les familles de Qâsim bey, Muhammad Kâshif, et le mîr liwâ Sulaymân bey. Voir les lettres de Murâd bey à Donzelot, n 51, du 20 muharram 1215/13 juin 1800 ; lettre $n^{\circ} 113$, du 21 dhû al-hijja 1215/5 mai 1801.

58. Correspondance de Napoléon Ier, t. IV, p. 463, $\mathrm{n}^{\circ} 3234,18$ fructidor an VI (4 septembre 1798).

59.Voir le Rapport sur les ordres du jour et les impôts relatifs aux provinces d'Isnâ, de Girgâ et d'Asyût, du 15 germinal an VII (7 avril 1799), carton $n^{\circ} 256$, qui se trouve dans le fonds relatif à l'expédition, à la Bibliothèque centrale.

60.Ordre du jour du général en chef Kléber, 28 fructidor an VII (14 septembre 1799), Kléber en Égypte, t. III, p. 50-52. 
61.Tableau des contributions de la province de Girguéh en argent, an VII, documents de

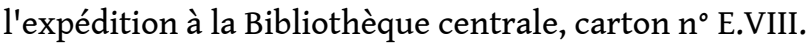

62. Lettre de Murâd bey à Donzelot, $n^{\circ}$ 90, du 4 jumâdâ I 1215/23 octobre 1800. De fait, les Anglais et les Ottomans déployaient des efforts considérables pour attirer les Mamelouks; ils leur avaient fait les mêmes offres que celles qui avaient été faites à Murâd bey, à savoir que la Sublime Porte prendrait pour eux des firmans qui garantiraient leur protection et leur sécurité.

63.Ibidem.

64.On peut en conclure à la responsabilité de Murâd bey en prenant deux exemples. Le premier concerne l'émir Ayyûb Kâshif qui s'était emparé d'une récolte de coton un peu avant le traité, ainsi que de l'enquête menée par Murâd où il fait état de sa volonté de payer le prix si nécessaire. Et le second concerne l'émir Muhammad al-Alfî durant la période de lutte contre les Français et la crainte exprimée par Murâd que « le susnommé ne soit un de nos Mamelouks ».

65.Lettre de Murâd bey à Donzelot, n ${ }^{\circ}$ 92, du 9 jumâdâ II 1215/28 octobre 1800 .

66. Voir, par exemple, la lettre $n^{\circ} 51$, qui donne un exemple complet et clair du contenu d'une ijâza.

67. Lettre de Murâd bey à Donzelot, nº 80, 19 rabî’ I 1215/12 août 1800.

68.Fonds des documents relatifs à l'expédition française, Bibliothèque centrale, carton $\mathrm{n}^{\circ} 212$, dossier sans numéro.

69. Lettre de Murâd bey à Donzelot, $\mathrm{n}^{\circ} 51$, du 10 muharram 1215/2 juin 1800 .

70.Lettre de Murâd bey à Donzelot, $\mathrm{n}^{\circ}$ 76, du 15 rabî' I 1215/8 août 1800 .

71.Lettre de Murâd bey à Donzelot, $n^{\circ} 58$, du 28 muharram 1215/21 juin 1800.

72.Lettre de Murâd bey à Donzelot, $n^{\circ} 72$, du 26 safar 1215/19 juillet 1800 .

73.Lettre de Donzelot au général en chef Menou, 10 thermidor an IX (1er décembre 1800). Le texte de cette lettre dans Nabîl al-Tukhî, op. cit., annexe n 6, p. 359-361.

74.Il semble que cette troupe de fuyards resta « planquée » dans le sud de la HauteÉgypte, puis se joignit, à la fin de l'expédition, à d'autres groupes pour gagner les rangs mamelouks. Al-Râfi'î écrit, d'après une source française de l'époque, que leur nombre atteignit 400. Voir 'Abd al-Rahmân al-Râfi'î, Ta'rîkh al-haraka al-qawmiyya wa tatawwur nizâm al-hukm fî misr, $2^{\mathrm{e}}$ partie, vol. 3, « al-Nahda al-masriyya », Le Caire, Dâr al-Macârif, 1958, p. 256.

75.Muhammad Fu'âd Shukrî, 'Abdallâh Jacques Menou wa-khurûj al-faransiyyîn min Misr, Le Caire, Dâr al-kitâb al-'arabî, 1952, p. 275, et H. Laurens, op. cit., p. 533.

76.La signature de la convention d'al-'Arîch, le 28 janvier 1800, est le plus important de ces événements. Elle laissait la perception du mîrî aux soins des Ottomans. Avec l'annulation du traité le 25 mars et la bataille d'Héliopolis, qui devait aboutir à la déroute des Ottomans, et ensuite, avec le déclenchement de la deuxième révolte du Caire qui dura jusqu'au 25 avril, les Français n'eurent pas la possibilité de lever l'impôt avant les mois de mai et juin. Voir les textes de la convention d'al-'Arîch, et en particulier les articles 15,16,18, qui faisaient interdiction aux Français de lever les impôts, « Rapport de Kléber à l'autorité administrative », paru dans ses mémoires, Kléber en Égypte, t. IV, p. 544-546; et voir aussi al-Gabartî, Mazhar al-taqdîs, $2^{\mathrm{e}}$ partie, p. 354-356.

77.Il avait été nommé par la Sublime Porte, après la signature de la convention d'al-'Arîsh, comme gouverneur de la Haute-Égypte. Après le recouvrement de l'impôt, il s'enfuit avec ses gens en Syrie, où il arriva très affaibli par les combats et le peu de 
ressources dont il disposait. Voir lettre de Murâd bey à Donzelot n ${ }^{\circ} 58$, du 28 muharram 1215/21 juin 1800.

78. Note manquante.

79.Al-Gabartî, op. cit., $2^{\mathrm{e}}$ partie, p. 397-398.

80.Lettres de Murâd bey à D. Donzelot, $n^{\circ}$ 52, du 11 muharram 1215/5 juin $1800 ; n^{\circ}$ 54, du 14 muharram 1215/7 juin 1800 et n 76, du 15 rabî̀' I 1215/6 juillet 1800 .

81.On peut lire dans le rapport de Beausillage, contrôleur des finances en Égypte au moment de l'expédition : « Pour que les Français parviennent à lever l'impôt dans chaque village, il faut envoyer une force armée, qui va de 80 à 100 hommes et, en dépit de cela, ils n'obtiennent que fort peu de choses et après des peines harassantes. » Le texte en est donné dans Ibrâhîm Zakî, al-Hâla al-mâliyya wa-l-tatawwur al-hukûmî wa-lijtimầ̂ fí 'ahd al-hamla al-faransiyya, s. 1. n. d., p. 92-96.

82.Lettres de Murâd bey à D. Donzelot, $n^{\circ}$ 54, du 14 muharram 1215/7 juin 1800.

83.Ceci devait surprendre à ce point Donzelot qu'il en fit état dans une lettre qu'il adressa au général en chef Kléber. Voir Pièces diverses et correspondance relatives aux opérations militaires et politiques de l'armée d'Orient en Égypte, Paris an IX (1801), p. 302.

84.Les forces mameloukes s'élevaient alors à 3 500-4 000 hommes. Cf. 'Abd al-Rahmân al-Râficî, op. cit., vol. II, p. 256.

85.Lettre de Murâd bey à Donzelot, $n^{\circ}$ 55, du 18 muharram 1215/11 juin 1800.

86.Lettre de Murâd bey à Donzelot, $\mathrm{n}^{\circ}$ 49, du 10 muharram 1215/3 juin 1800.

87.Lettre de Murâd bey à Donzelot, $n^{\circ} 76$ du 15 rabî' I 1215/6 août 1800 .

88. Note manquante.

89.Voir le mémoire de Beausillage, dans Ibrâhîm Zâkî, op. cit., p. 96.

90.Le bois était rare en Égypte, mais les caravanes de Dongola fournissaient Girgâ en bois de charpente utilisés dans la construction des chalands. Cf. Ilhâm Dhahab, Misr fi Kitâbât al-rahhâla wa-l-qanâsil al-faransiyyîn fîl-qarn al-thâmin 'ashar, silsilat Târîkh almisriyyîn (coll. « Histoire des Égyptiens »), n 52, Le Caire, al-Hay'a al-'âmma li-l-kitâb, 1992, p. 178-179.

91.Lettres de Murâd bey à Donzelot, n 80, 19 rabî' I 1215/10 juillet 1800 et nº 79, du 26 rabî' I 1215/17 juillet 1800 .

92.Nabil al-Tukhî signale qu'il existe, dans les archives du tribunal d'Asyût, de nombreux exemples de ce que les bateliers donnaient volontiers leurs bateaux en location aux Français. Voir Nabîl al-Tûkhî, op. cit., p. 278.

93.Lettre de Murâd bey à Donzelot, $n^{\circ}$ 79, du 26 rabî̀ I 1215/17 juillet 1800 .

94.Lettre de Murâd bey à Donzelot, $\mathrm{n}^{\circ} 75$, du 10 rabî' I 1215/1er août 1800 .

95.Sur les marchandises africaines apportées par les caravanes du Darfour et du Sennar, voir, dans la Description de l'Égypte, l'article de Gérard sur la vie économique en Égypte au XVIII : Gérard, "al-Hayât al-iqtisâdiyya fî Misr fî-l-qarn al-thâmin 'ashar ", t. I, Wasf misr, vol. IV, traduction Zuhayr al-Shâyib, 1978, p. 236-250.

96.Lettre de Murâd bey à Donzelot, $\mathrm{n}^{\circ}$ 75, du 10 rabî' I 1215/1er août 1800.

97.Lettre que, par bonheur, nous avons trouvée parmi l'ensemble des lettres d'Ibn Wâfî, $n^{\circ} 115$, sans date.

98. Note manquante.

99.Il suffit, pour se convaincre de l'importance de ce commerce, de savoir que pour l'année 1796 la valeur des importations sur le marché égyptien étaient de 62339225 paras, et que les revenus liés aux taxes douanières était de 5435362 ; ce qui représente environ $28 \%$ du total des revenus des Douanes pour l'ensemble de l'Égypte. Voir, dans la Description de l'Égypte, l'article d'Estève sur l'organisation financière et administrative 
dans l'Égypte ottomane : Estève, « al-nizâm al-mâlî wa-l-idâri fî Misr al-'uthmâniyya ", Wasf Misr, vol. V, p. 211 ; 'Abd al-Rahîm 'Abd al-Rahmân, Fusûl min târîkh Misr al-iqtisâdî wa-l-ijtimầîfî l-'ahd al-'uthmânî, silsilat Târîkh al-misriyyîn, n 28 , Le Caire, al-Hay'a al-âmma li-l-kitâb, 1990, p. 242-243.

100.Ordre du général en chef Kléber, le 23 prairial an VIII (12 juin 1800), Kléber en Égypte, t. IV, p. 966-967.

101.Fâtima al-Hamrâwî, op. cit., p. 363.

102.Lettre de Murâd bey à Donzelot, nº 80, du 19 rabî’ 1215/12 août 1800.

103.ibidem.

104.C'est ce qui ressort d'une lettre du général Lapanouse, directeur des Douanes d'Asyût, à Menou. Voir Nabîl al-Tûkhî, op. cit., p. 274-275.

105.Lettre de Murâd bey à Donzelot, sans numéro, du 14 jumâdâ I 1215/3 octobre 1800. 106.Cf. Nabîl al-Tûkhî, op. cit., p. 275.

107.Lettre de Murâd bey à Donzelot, $n^{\circ}$ 102, 12 sha'bân 1215/29 décembre 1800.

108.Ibidem.

109.Pour juger de l'hostilité des Ottomans envers les Mamelouks et des efforts qu'ils firent pour les priver de tout rôle politique, voir Gabartî, 'Ajâ'ib al-âthâr fîl-l-tarâgim wa-lakhbâr, Le Caire, Matba'at al-anwâr al-muhammadiyya, vol. III, p. 285-289, 295, 296, 312-316, 318, 321-323, 326-329, 331-339, 341-342, 353-356, 361-364,366-372.

110.Voir sa biographie dans Gabartî, 'Ajâ'ib., t. III, p. 237-242.

INDEX

Mots-clés : expédition d'Égypte, histoire

\section{AUTEUR}

\section{NÂSIR SULAYMÂN}

Université du Caire 